\title{
The use of manual hyperinflation in airway clearance
}

\author{
L. Denehy
}

\begin{abstract}
The use of manual hyperinflation in airway clearance. L. Denehy. ERS Journals Ltd 1999. ABSTRACT: Manual lung hyperinflation (MH) is one of a number of techniques which are employed by the physiotherapist in the critical care setting. The technique was first described with physiotherapy 30 yrs ago and commonly involves a slow, deep inspiration, inspiratory pause and fast unobstructed expiration. The use of $\mathrm{MH}$ varies between and within countries. It is commonly employed by physiotherapists to assist in the removal of secretions and re-expand areas of atelectasis.

Despite the popularity of the technique, research examining its efficacy is conflicting, especially the effect of MH on cardiovascular parameters. Recent studies examining mucociliary transport in intubated and ventilated patients have shown impaired clearance of secretions, but research evaluating the role of MH specifically in airway clearance is scant. The use of the additional physiotherapy techniques, gravity assisted drainage and chest wall vibrations, may enhance the efficacy of $M H$ in promoting airway clearance, but further research is necessary.

Controversy exists regarding the safety and effectiveness of application of manual lung hyperinflation in intubated patients. Clearly, more randomized controlled studies are necessary in order to provide a sound scientific rationale for the application of manual lung hyperinflation in the treatment of critically ill patients. Eur Respir J 1999; 14: 958-965.
\end{abstract}

\author{
Correspondence: L. Denehy \\ School of Physiotherapy \\ Faculty of Medicine, Dentistry and Health \\ Sciences \\ The University of Melbourne \\ Parkville 3052 \\ Australia \\ Fax: 61393444188
}

Keywords: Airway clearance

intensive care

manual hyperinflation

mechanical ventilation

physiotherapy

Received: November 201997

Accepted after revision December 151998
Manual lung hyperinflation (MH) is one of a number of techniques which are employed by the physiotherapist in the critical care setting. This paper will review the application of $\mathrm{MH}$ with specific reference to its role in airways clearance. Manual hyperinflation is most commonly used as a treatment technique in the management of intubated patients. Intubation and mechanical ventilation are indicated in acute reversible respiratory failure [1]. However, application of intermittent positive pressure ventilation is not without adverse pulmonary physiological effects. These include: reduced functional residual capacity (FRC), increased ventilation:perfusion mismatching, decreased compliance and a reduction in surfactant $[2,3]$. In addition, intubated critically ill patients are at high risk of developing nosocomial infections, especially nosocomial pneumonia [4]. These infections are an important cause of morbidity and mortality in the intensive care unit (ICU) [5]. The goals of physiotherapy management of patients in the ICU are to maximize musculoskeletal performance and oxygenation, maintain or improve cardiopulmonary function and prevent complications by improving mucociliary clearance and alveolar expansion $[2,6]$.
The role of the physiotherapist in the management of the intubated patient is not solely directed toward respiratory care. Attention to neurological dysfunction and the musculoskeletal needs of the patient are also important. Accurate assessment is essential. Techniques should not be routinely applied, rather individual problems should be prioritized and appropriate techniques chosen which address the specific needs of each patient.

\section{Definition of manual hyperinflation}

Manual hyperinflation was originally defined [7] as inflating the lungs with oxygen and manual compression to a tidal volume $(V \mathrm{~T})$ of $1.0 \mathrm{~L}$, requiring a peak in-spiratory pressure of between 20 and $40 \mathrm{cmH}_{2} \mathrm{O}$. More recent definitions include: providing a larger $V \mathrm{~T}$ than baseline $V \mathrm{~T}$ to the patient $[8]$ and using a $V \mathrm{~T}$ which is $50 \%$ greater than that delivered by the ventilator [9]. The technique involves using a rebreathing or self-inflating circuit to provide the manual breath, usually with the addition of $100 \%$ oxygen. It was first described with physiotherapy by CLEMENT and Hubsch [10] in 1968. This paper and that

Previous articles in this Series: No. 1. E. Houtmeyers, R. Gosselink, G. Gayan-Ramirez, M. Decramer. Regulation of mucociliary clearance in health and disease. Eur Respir J 1999; 13: 1177-1188. No. 2. C.P. van der Schans, D.S. Postma, G.H. Koëter, B.K. Rubin. Physiotherapy and bronchial mucus transport. Eur Respir J 1999; 13: 1477-1486. No. 3. E. Houtmeyers, R. Gosselink, G. GayanRamirez, M. Decramer. Effects of drugs on mucus clearance. Eur Respir J 1999; 14: 452-467. 
by WINDSOR et al. [7] in 1972 described the technique of $\mathrm{MH}$ in detail. These descriptive papers, predominantly based upon case reports, expounded the effectiveness of the technique for removing secretions in acutely ill uncooperative patients. In these papers, $\mathrm{MH}$ was performed by an anaesthetist and the physiotherapist used chest wall vibrations through the expiratory phase of each breath. The technique as described above has been used with few modifications since this time. Until recently, only limited research was available which scientifically examined the technique of $\mathrm{MH}$, its methodology, reproducibility, efficacy and indications in clinical practice. These issues will be discussed in more detail below.

The use of $\mathrm{MH}$ by physiotherapists varies between and within countries. Two separate surveys compared the use of the technique by physiotherapists in Hong Kong, the UK and Australia. KING and Morrell [11] in 1992, found that of the 176 public hospitals surveyed in the UK (of which 58\% responded), all respondents used $\mathrm{MH}$ as a treatment technique in the ICU. JonEs et al. [12] in 1992, compared the frequency of use of $\mathrm{MH}$ in hospitals in Hong Kong, Australia and the UK. The results of these surveys are presented in figure 1 . The proportion of physiotherapists using $\mathrm{MH}$ in the UK in the survey of JONES et al. [12] was significantly different from that of KING and MorRell [11]. The reasons for this may be the differing criteria used for selection of hospitals in each survey. The role of the hospital, whether teaching or community based, or the location (urban or rural) may have contributed to the different results.

\section{Indications}

The indications for the use of $\mathrm{MH}$ by physiotherapists in intubated patients vary, but may include one or a combination of the following: to improve oxygenation pre- and postsuctioning, to mobilize excess bronchial secretions and to reinflate areas of the collapsed lung [13, 14]. The perceived benefits of using $\mathrm{MH}$ in the UK [11] are presented in figure 2. The precautions and contra-indications for use of $\mathrm{MH}$ vary between therapists and units. The adverse consequences of $\mathrm{MH}$ result from its

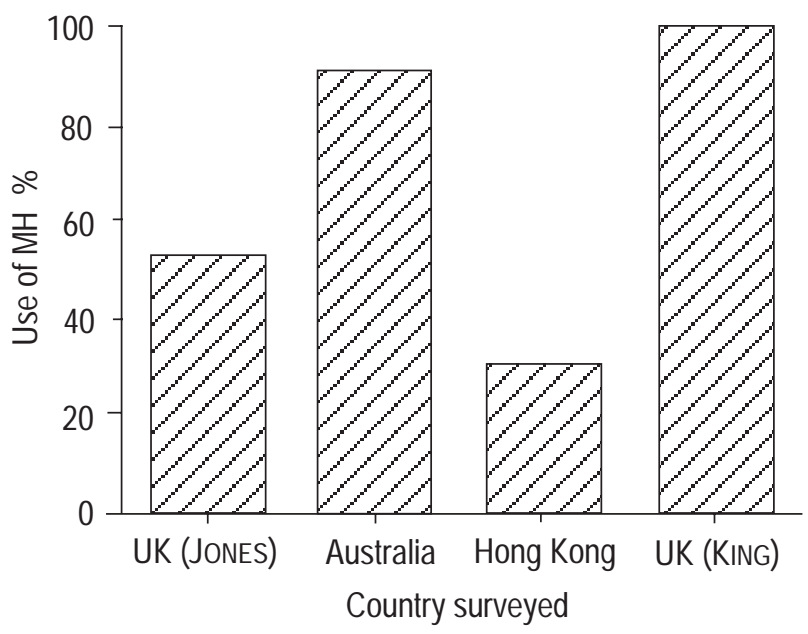

Fig. 1. - The frequency of use of manual hyperinflation (MH) in intensive care units in the UK; Australia and Hong Kong adapted from results of two surveys by KING and MorReLL [11] and JONEs et al. [12].

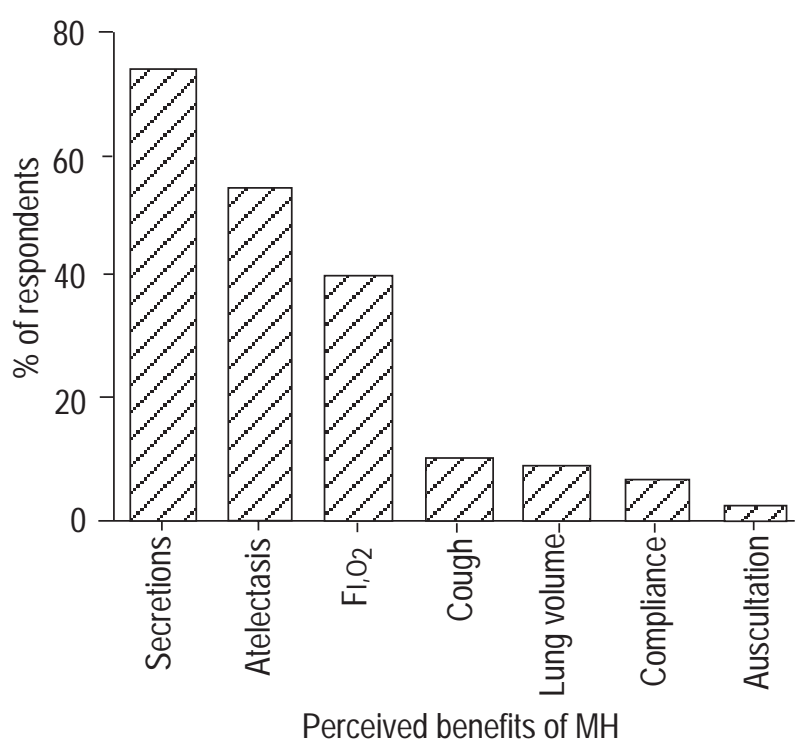

Fig. 2. - Perceived benefits of manual hyperinflation (MH) amongst respondent physiotherapists surveyed in the UK. (Adapted from [11].)

effects upon cardiovascular haemodynamics and intrapleural pressures. The precautions for its use reflect these and may include $[11,23]$ : unstable cardiovascular system; undrained pneumothorax; severe bronchospasm; high peak inspiratory pressure (PIP); positive end-expiratory pressure $(\mathrm{PEEP})>10 \mathrm{cmH}_{2} \mathrm{O}$; raised intracranial pressure; and acute pulmonary oedema.

The precise definition of an unstable cardiovascular system and the level of PIP accepted also vary between ICUs. Given the risks for alveolar trauma [15], a more cautious approach to the use of $\mathrm{MH}$ in ventilated patients may be to consider a maximum PEEP of $7.5 \mathrm{cmH}_{2} \mathrm{O}$ rather than the $10 \mathrm{cmH}_{2} \mathrm{O}$ documented in most physiotherapy literature.

There is considerable controversy in recent literature about the safety of application of positive pressures in ventilated patients with acute lung pathology [16]. High airway pressures have been linked to the development of barotrauma. Apart from extra-alveolar air, subtle physiological and morphological lung changes may occur as a result of high airway pressures and high lung volumes [17]. Peak inspiratory pressures between 40 and 50 $\mathrm{cmH}_{2} \mathrm{O}$ have been associated with alveolar rupture [18]. Others suggest an association between barotrauma and high levels of PEEP [16]. There is now some evidence that "volutrauma" may be the more appropriate term and that transalveolar pressure is the important factor. Much of the research to date uses animal models and is thus far from conclusive, in part owing to the difficulty involved in measuring regional lung volumes in vivo. However, in managing acute respiratory distress syndrome (ARDS) the focus of ventilatory management is on avoiding inflation pressures and $V \mathrm{~T}$ which overdistend the reduced number of functional alveoli $[15,17]$. Given the variable nature of the pressure and volume changes associated with $\mathrm{MH}$, its use in ARDS is questionable. Since many patients with ARDS have poor pulmonary compliance and high levels of PEEP, treatment with $\mathrm{MH}$ is most often not indicated. 


\section{Description of the technique}

The technique of $\mathrm{MH}$ is presented in figure 3. It commonly involves a slow, deep inspiration, inspiratory pause and unobstructed expiration. The slow, deep inspiration increases $V \mathrm{~T}$ and the pause allows filling of alveoli with slow-time constants [19]. The rapid, unobstructed expiratory phase enhances clearance of bronchial secretions [10]. The technique has been compared to a cough, where a deep inspiratory effort is followed by a very rapid expulsive flow of air [13, 20]. Manual hyperinflation is sometimes called "bagging" or "bag squeezing", but differs from the bagging performed during resuscitation or ventilator circuit changes in that it hyperinflates the lungs by increasing resting $V \mathrm{~T}$ [13]. It may be performed by anaesthetists, physiotherapists and nurses. In a survey in the UK [11] it was found that physiotherapists and nurses performed the technique in $79 \%$ of hospitals whilst anaesthetists were the sole operators in $8 \%$ and nurses in $3 \%$ of the hospitals surveyed. Nurses performed $\mathrm{MH}$ in more than one-third of hospitals surveyed in the UK and Australia [12]. The technique of MH used by ICU nursing staff has shown wide discrepancy in volumes, pressures and pressure waveforms generated [9].

A recent study sought to define the technique of $\mathrm{MH}$ in terms of physiological parameters [8]. This involved 10 physiotherapists working in ICUs who used MH. Using a test lung model and different compliance settings, these authors found physiotherapists varied the size of the $V \mathrm{~T}$ delivered and the use of the inspiratory hold. Mean $\pm \mathrm{SD}$ $V$ T was found to be $1481.1 \pm 242 \mathrm{~mL}$. The mean \pm SD peak airway pressure $(P$ aw $)$ was $20.7 \pm 6.6 \mathrm{cmH}_{2} \mathrm{O}$ and mean inflation rate 13 per minute. The parameters measured were significantly influenced by the type of circuit used. As compliance settings were increased $V \mathrm{~T}$ reduced and airway pressure increased. In another study of 16 physiotherapists [21] also using test lungs, results were similar with a mean $V \mathrm{~T}$ of $1140.6 \mathrm{~mL}$ and $P$ aw of 25.1 $\mathrm{cmH}_{2} \mathrm{O}$. However, in this study the mean inflation rates were lower (10.3 per minute). Again the type of circuit used had a significant influence on the results. The mean inflation rate produced will effect the patient's minute ventilation and consequently the arterial blood gases. This factor should be closely monitored during performance of the technique and adjusted to appropriate levels

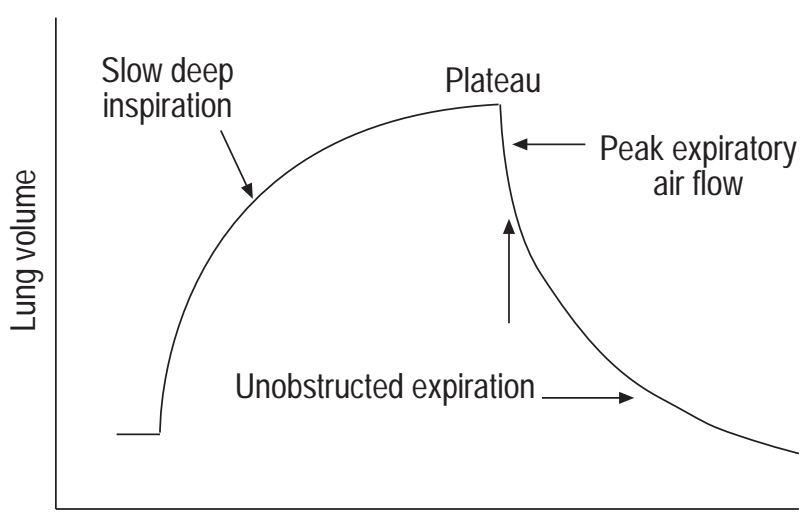

Fig. 3. - A diagrammatic representation of the commonly used technique in manual lung hyperinflation. (Adapted from [10].) for each patient based on their ventilation requirements. The inter-therapist reliability was measured as part of this study and intraclass correlation coefficients were found to be good for both $V \mathrm{~T}$ and $P$ aw. Improved reliability was obtained with the Air Viva circuit (Ohmeda, Sydney, Australia) compared to the Mapleson C (consisting of Heidbrink MIE Superlight 7003 expiratory valve and 2-L anaesthetic bag; Ohmeda). The reliability of application of $\mathrm{MH}$ in patient populations remains to be studied, to the authors knowledge there is no published data which measures this. Percentage variations in $V \mathrm{~T}$ of between -33 and $+127 \%$ of baseline values have been reported during $\mathrm{MH}$ in stable ventilated ICU patients [9]. In the same study, $P$ aw varied between -30 and $+250 \%$ during $\mathrm{MH}$.

The third component of the MH technique which may vary with differing equipment and operator technique, is expiratory flow. This is thought to be a critical factor which influences secretion mobilization [22]. However, this has not been extensively examined in the literature. JONES et al. [23] measured expiratory flow rates in both the Laerdal and Mapleson C circuits and found that the Laerdal circuit (Laerdal Medical Corp., Victoria, Australia) produced a higher peak expiratory flow, and that flow increased as the pressure to which hyperinflation was performed increased. Therapists were able to reproduce these flows more reliably with the Laerdal circuit. Extrapolation of these results to in vivo conditions can only be made with caution. The addition of chest compression and vibrations to $\mathrm{MH}$ (delivered by a Laerdal bag) in nine intubated patients has been shown to significantly increase maximum expiratory flows [24].

\section{Equipment}

The choice of equipment employed in different ICUs appears to be a subjective decision based upon individual preference [23]. The most common breathing circuits used in Australia, the UK and Hong Kong are the Laerdal, Air Viva, Mapleson C and Magill (Ohmeda MA105). The Mapleson $\mathrm{C}$ and Magill circuits are very similar, as are the Air Viva and Laerdal. Some of these circuits are shown in figure 4 . The type of circuit used has been shown in the two previously discussed studies to influence delivered volumes and pressures. Table 1 presents this data. It can be seen that there is considerable variation in these values even with similar circuits. These results support those of Hess et al. [25], who also found that individual variation in technique affected outcome. The reasons for this could be the experience of the operator, familiarity with the circuit and original training in skill acquisition [8].

One of the areas of controversy in the use of $\mathrm{MH}$ is whether increasing $V \mathrm{~T}$ or hyperinflating to specific airway pressures provides the most effective technique, especially in reinflating collapsed lung segments. Manual hyperinflation was and still is defined as a technique which should increase the VT. Recently, Rothen et al. [26], found that inflation to airway pressures of $40 \mathrm{cmH}_{2} \mathrm{O}$ in normal subjects undergoing general anaesthesia was more effective in recruiting the atelectatic lung than hyperinflating to twice the $V \mathrm{~T}$. Extrapolation of this information to lungs with existing pathology should be made with caution. However, airway pressures reached in the studies outlined in table 1 were generally well below $40 \mathrm{cmH}_{2} \mathrm{O}$. These 

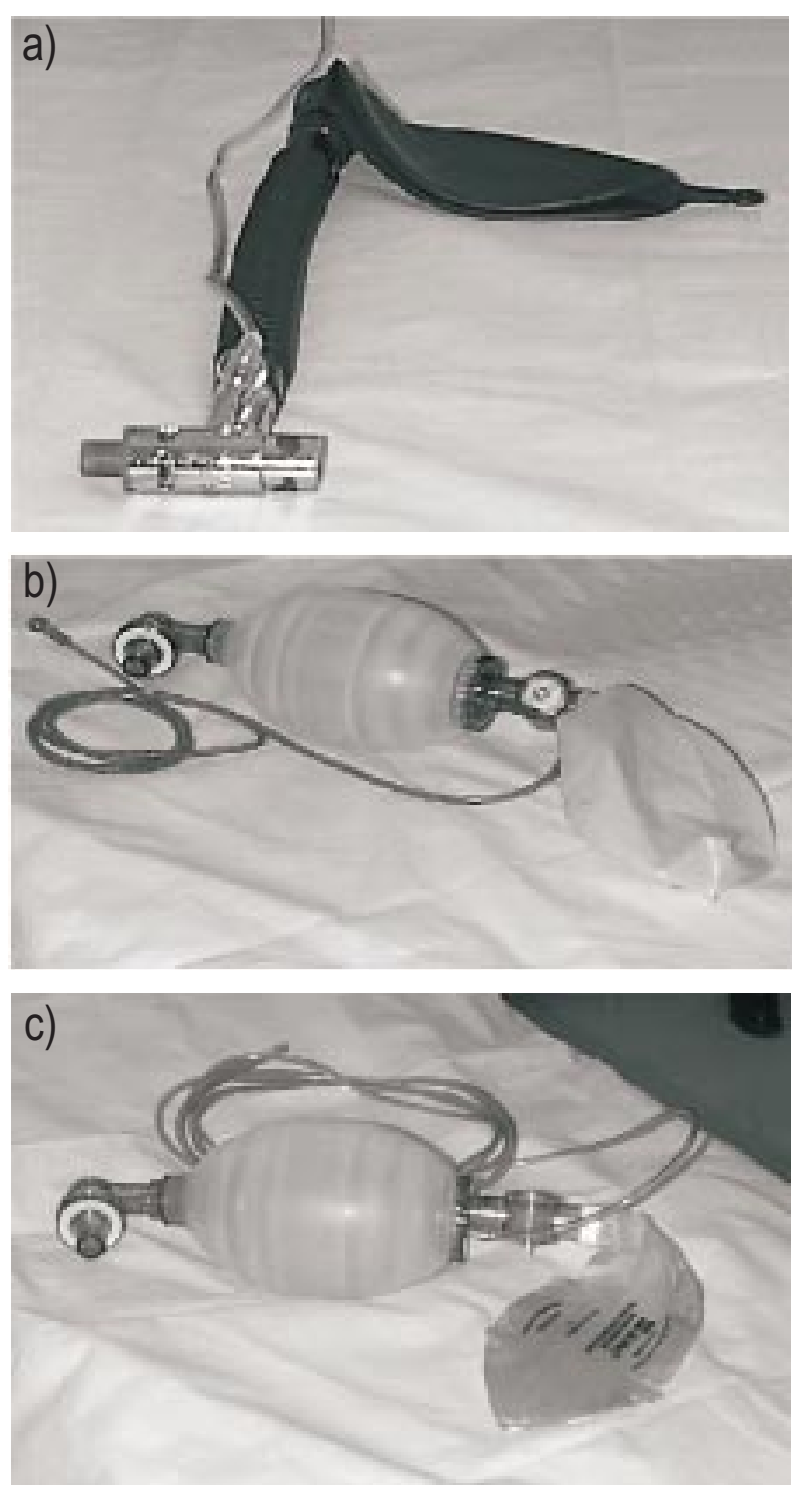

Fig. 4. - Different types of bagging circuit. a) Magill, b) Laerdal, and c) Air Viva.

pressures may reduce the risk of causing barotrauma or volutrauma, but are they sufficient to effectively recruit collapsed lung or promote secretion clearance? In light of the research by ROTHEN et al. [26], a manometer should be included in the $\mathrm{MH}$ circuit. It is acknowledged that the pressure obtained at the manometer may not accurately reflect intrapulmonary pressures. However, the presence of a manometer may enhance safety and possibly effectiveness of the technique by allowing therapists to inflate to a known pressure. The pressure or volume dilemma needs further clarification.

\section{Airway clearance and manual hyperinflation}

Normal clearance of the airways takes place by two principal means, mucociliary action and cough. Alveolar clearance may also deal with peripheral airway secretions $[27,28]$. When either or both of these mechanisms are
Table 1. - A comparison of results for the Laerdal, Air Viva, Magill and Mapleson $\mathrm{C}$ manual hyperinflation circuits

\begin{tabular}{|c|c|c|c|c|}
\hline $\begin{array}{l}\text { First } \\
\text { author }\end{array}$ & [Ref.] & Circuit & $\begin{array}{c}\text { Tidal } \\
\text { volume } \\
\text { mL }\end{array}$ & $\begin{array}{c}\text { Peak airway } \\
\text { pressure } \\
\mathrm{cmH}_{2} \mathrm{O}\end{array}$ \\
\hline \multirow[t]{2}{*}{ SмIтн } & \multirow[t]{2}{*}[21]{} & Air Viva & 787.5 & 16.4 \\
\hline & & Mapleson C & 1494.1 & 35.5 \\
\hline \multirow[t]{2}{*}{ MCCARREN } & \multirow[t]{2}{*}{ [8] } & Magill & 1663.1 & 24.8 \\
\hline & & Laerdal & 1315.3 & 16.9 \\
\hline
\end{tabular}

Results are mean values for all therapists using two or three compliance settings with the test lungs. Data are adapted from McCARREn et al. [8] and SMith et al. [21].

impaired, such as when a patient is intubated and has excess bronchial secretions, movement of secretions may be achieved by two-phase gas liquid transport [29, 30]. In this nonciliary dependent phasic flow, energy is transmitted from the moving air to the static liquid, shearing and moving the liquid in the direction of flow [27, 31]. The major factors influencing flow include: surface velocity, liquid layer thickness and the rheological properties of the liquid [31]. During MH, the high expiratory flows thought to be produced, together with dynamic change in airway diameter, may result in annular and mist flow, both within the trachea and downstream from the equal pressure point [28]. It is postulated that expiratory flow velocity needs to be higher than inspiratory for this clearance to occur [29], and that it may only occur if the mucus layer exceeds a critical thickness [30]. While this is a somewhat oversimplification of a complex process, it seems possible that the mechanism of two-phase flow may contribute to clearance of secretions in intubated patients receiving $\mathrm{MH}$ treatment.

In humans, the average tracheal transport velocity using bronchofibreoptic methods has been reported to be $\sim 10$ $\mathrm{mm} \cdot \mathrm{min}^{-1}$ [32]. Recently, mucociliary transport was measured in 32 ventilated ICU patients using radiolabelled albumin and a scintillation camera [33]. The results of this study showed that the median bronchial mucous transport (BMT) was $0.8 \mathrm{~mm} \cdot \mathrm{min}^{-1}$ in the right main bronchus and $1.4 \mathrm{~mm} \cdot \mathrm{min}^{-1}$ in the left main bronchus. Pulmonary complications occurred in 14 of the 32 patients and these patients had a significantly lower BMT than patients without pulmonary complications. The authors concluded that patients in the ICU have impaired mucous transport which is associated with retention of secretions and pneumonia. Apart from intubation, the effects of drugs, paralysing agents, ventilation with high oxygen concentrations [34], and suction induced lesions of the mucous membrane [35] may play a significant role in altering mucociliary clearance in ventilated patients. The work of KONRAD et al. [33] therefore provides an indication for the use of secretion clearance techniques in these patients.

Although the technique of $\mathrm{MH}$ was initially developed to clear the airways of secretions, early reports of efficacy were anecdotal [7]. Until recently, no randomized controlled trials had been published which measure the effectiveness of secretion clearance as a primary outcome of using MH. Despite this, many physiotherapists in the UK and Australia use $\mathrm{MH}$ as part of their treatment regimen, and in fact $74 \%$ of physiotherapists in the UK 
who use MH perceive its main benefit to be removal of excessive secretions [11]. In a recent study, Hodgson et al. [36] measured secretions produced by 18 ventilated intensive care patients receiving $\mathrm{MH}$ positioning and suction compared to positioning and suction alone. They found a significant increase in the wet weight of secretions produced following the treatment with $\mathrm{MH}$. In a study of the effects of chest physiotherapy upon the resolution of lobar atelectasis [37], secretion clearance was measured using the volume of secretions cleared to the nearest $5 \mathrm{~mL}$. This was not a primary outcome measure in this study, but the authors reported that the volume of secretions cleared was not different between the groups who received different physiotherapy treatment regimens. These included using gravity-assisted drainage with and without vibrations or MH and suction alone. The inexact measurement of secretion volume in this study may have masked any differences which may exist. Resolution of atelectasis was the primary outcome of interest in this study. The authors found that the addition of gravity-assisted drainage with $\mathrm{MH}$ and suction was more effective in assisting radiological resolution of atelectasis than $\mathrm{MH}$ and suction alone. The small sample sizes used in this study ( $\mathrm{n}=7$ in each of five groups) limit its generalizability, however, the study does add to the limited existing research in this field.

Additional factors which may enhance the effectiveness of $\mathrm{MH}$ in removing secretions, are its performance in a gravity assisted drainage position, with the addition of chest wall vibrations throughout the expiratory phase of the technique. Gravity-assisted drainage or postural drainage can be defined as placing the body into a position that allows gravity to assist in the drainage of mucous from the lung periphery to the upper airway [38]. The technique has been used since the beginning of this century [39] and the positions used are based on the anatomy of the bronchial tree. Intermittent drainage was advocated by NELSON [40] in 1934 but scientific evaluation of the technique has only more recently been documented [39]. Most previous research has focused on patients with cystic fibrosis. In these patients with impaired airway clearance, gravity assisted drainage has been shown to be effective in removing excess secretions from the lungs [41-43]. It has been demonstrated [33] that intubated patients have slower mucociliary clearance, which is compounded by bypassing of the upper airways and less than optimal humidification of secretions [6]. It could, therefore, be argued that intubated patients require help with mucociliary clearance in a similar way to patients with cystic fibrosis.

The addition of gravity assisted drainage in patient management may also improve lung compliance. This may be achieved by facilitating drainage of secretions [44] or by altering regional compliance of the lung [45]. In light of the previously discussed work by KONRAD et al. [33] and research in patient populations with excessive secretions, the use of gravity-assisted drainage positions should be advocated where patients are receiving $\mathrm{MH}$, with the aim of increasing secretion clearance. In some patients, the use of the head down tilt position may require caution or be contra-indicated $[2,46]$. Continuous monitoring of cardiovascular and respiratory parameters is essential during all forms of physiotherapy treatment in the ICU.
The application of chest wall vibrations during $\mathrm{MH}$ has been advocated since the technique was first described [10]. These involve a vibratory action by the hands placed on the chest wall in the direction of normal movement of the ribs, transmitted through the chest using body weight [47]. They are performed throughout expiration. Much of the available research has been carried out in patients with cystic fibrosis and chronic bronchitis [41, 43]. Few studies are available which examine the effectiveness of vibrations in intubated patients in isolation, as this technique is most commonly performed in a gravity-assisted drainage position, often during $\mathrm{MH}$. As discussed earlier in this review vibrations have been shown to increase maximum expiratory flow rates [24]. No attempt was made to relate this to secretion clearance in the patients studied. The work of STILLER et al. [37] previously discussed in this paper, compared the effects of the addition of vibrations to $\mathrm{MH}$, suction and gravity-assisted drainage in patients in the ICU. They concluded that vibrations could be omitted from treatment without any loss of effect on the resolution of acute lobar atelectasis. This study has methodological limitations and the primary goal of physiotherapy treatment was to improve lung collapse. However, these two conflicting papers examining vibrations highlight the paucity of sound scientific evidence upon which to make clinical treatment decisions. It is the author's view that until more evidence is available which examines the effectiveness of the technique in isolation, vibrations could be included in a treatment regimen with $\mathrm{MH}$ where removal of secretions is the main goal of treatment. The efficacy of the technique could then be assessed for each individual patient.

The instillation of a small bolus of normal saline into the endotracheal tube prior to suctioning is a technique which is often used and is thought to help wash out secretions [48]. The effectiveness of this technique has not been substantiated in the literature [49]. The value of saline instillation prior to, or during, $\mathrm{MH}$ to improve secretion clearance has not, to the author's knowledge, been studied.

It has been suggested [50] that conventional chest physiotherapy (including gravity-assisted drainage, vibrations), only addresses one aspect of the oxygen delivery pathway and is therefore ineffective. The use of positioning, exercise and mobililization is advocated in preference to any of the other forms of management. However, whilst these techniques are also important in the management of intubated patients, and should contribute to improved secretion clearance and lung volumes, the use of conventional management should not be completely discarded [51]. Clearly, more randomized controlled research in this patient group will enable physiotherapists to choose appropriate and effective management strategies for individual patient problems.

Despite the popularity of the technique, research examining the use of $\mathrm{MH}$ is conflicting, sample sizes are generally small and methodology often flawed. In addition, many of these papers are difficult to compare owing to the varying technique of $\mathrm{MH}$ employed, concurrent treatment techniques used and the different patient populations studied. There is support for the use of $\mathrm{MH}$ to improve atelectasis [26, 52-54], lung compliance [36, 44] and gas exchange [36, 54-56]. Others have reported no change [57-59] or deterioration [60] in gas exchange and the effect of the technique upon haemodynamics remains 
Table 2. - A summary of results of relevant manual hyperinflation $(\mathrm{MH})$ literature

\begin{tabular}{|c|c|c|c|c|c|}
\hline First author & [Ref.] & $\begin{array}{l}\text { Subjects } \\
\mathrm{n}\end{array}$ & Techniques studied & Outcomes measured & Change in outcomes with $\mathrm{MH}$ \\
\hline GormEnZANO & {$[60]$} & 42 & MH, positioning & Gas exchange & $\begin{array}{l}\text { Variable } \mathrm{Pa}_{\mathrm{a}} \mathrm{O}_{2} \\
\text { Increased } \mathrm{Pa}_{\mathrm{a}}, \mathrm{CO}_{2}\end{array}$ \\
\hline Hodgson & [36] & 18 & $\begin{array}{l}\text { MH \& positioning or } \\
\text { positioning alone }\end{array}$ & Gas exchange $C$ tot & $\begin{array}{l}\text { Improved } C \text { tot, } S_{\mathrm{a}}, \mathrm{O}_{2} \text {, increased } \\
\text { sputum wet weight }\end{array}$ \\
\hline JONES & [44] & 20 & $\begin{array}{l}\text { MH \& positioning versus } \\
\text { percussion \& positioning }\end{array}$ & $\begin{array}{l}\text { Sputum MAP, HR } \\
\text { Ctot } \\
\text { Gas exchange }\end{array}$ & $\begin{array}{l}\text { No change } \mathrm{MAP}, \mathrm{HR}, \mathrm{Pa}_{\mathrm{a}} \mathrm{O}_{2} / F \mathrm{I}, \mathrm{O}_{2} \\
\text { Improved } C \text { tot, } S \mathrm{a}, \mathrm{O}_{2} \\
\text { No change with persussion }\end{array}$ \\
\hline MARINI & [52] & 31 & $\begin{array}{l}\text { MH, GAD percussion } \\
\text { versus FOB }\end{array}$ & $\begin{array}{l}\text { CXR resolution } \\
\text { Gas exchange }\end{array}$ & $\begin{array}{l}\text { No significant differences in } \\
\text { improvement between FOB \& } \\
\text { physiotherapy }\end{array}$ \\
\hline NovaK & [59] & 16 & $\begin{array}{l}\text { MH \& positioning versus } \\
\text { hyperoxygenation and suction }\end{array}$ & $\begin{array}{l}\text { Gas exchange } \\
\text { Ctot }\end{array}$ & $\begin{array}{l}\text { No differences in groups } \\
\text { No reduction in gas exchange }\end{array}$ \\
\hline SINGER & [9] & 18 & Supine MH & $\begin{array}{l}\text { MH } V \mathrm{~T} \\
\text { MH PIP } \\
\text { CO, HR, MAP }\end{array}$ & $\begin{array}{l}\text { No change in HR, MAP } \\
\text { Fall in CO } \\
\text { Variable MH } V \text { T \& } P \text { aw }\end{array}$ \\
\hline StILler & [53] & 35 & $\begin{array}{l}\mathrm{MH} \\
\mathrm{GAD} \\
\text { vibrations }\end{array}$ & $\begin{array}{l}\text { CXR resolution } \\
\text { Gas exchange } \\
\text { Sputum }\end{array}$ & $\begin{array}{l}\text { GAD with MH more effective } \\
\text { in CXR resolution } \\
\text { No change in } \mathrm{Pa}_{\mathrm{a}} \mathrm{O}_{2} / \mathrm{FI}_{1} \mathrm{O}_{2} \text { or } \\
\text { sputum volume }\end{array}$ \\
\hline
\end{tabular}

GAD: gravity-assisted drainage; FOB: fibreoptic bronchoscopy; $C$ tot: total compliance; MAP; mean arterial blood pressure; HR: heart rate; $V$ T: tidal volume; PIP: peak inspiratory pressure; $\mathrm{CO}$ : cardiac output; $\mathrm{CXR}$ : chest radiograph; $P \mathrm{a}, \mathrm{O}_{2}$ : arterial oxygen tension; $\mathrm{Pa}_{\mathrm{a}} \mathrm{CO}_{2}$ : arterial carbon dioxide tension; $\mathrm{FI}_{\mathrm{I}} \mathrm{O}_{2}$ : inspiratory oxygen fraction; $\mathrm{S}_{\mathrm{a}, \mathrm{O}_{2}}$ : arterial oxygen saturation; $P$ aw: airways pressure.

controversial. Reductions in cardiac output have been reported $[9,57]$, whilst other studies report no changes in mean arterial blood pressure or heart rate $[9,36]$. Table 2 summarizes the relevant research literature on $\mathrm{MH}$.

\section{Summary and recommendations}

The recommendations from reviewing the literature regarding $\mathrm{MH}$ are that: 1) education of therapists is essential to improve reliability and, potentially, effectiveness of the technique; 2) outcomes of MH depend upon the skill of the practitioner and type of equipment used. This fact must also be considered when critically reviewing the literature; 3 ) inclusion of a manometer in the circuit should be mandatory; 4) an optimal treatment regimen for MH needs to be established. This should include dosage, patient position and levels of pressures and volumes which are necessary to achieve effectiveness and maintain patient safety; 5) the types of patient conditions which respond best to treatment with MH need to be elucidated; 6) more research is necessary using secretion clearance as a primary outcome measure when studying the effects of $\mathrm{MH}$; and 7) research examining the longer term outcomes of physiotherapy management in intubated patients is needed whilst acknowledging that controlled research in this area is difficult.

The role of manual hyperinflation in airway clearance remains unclear. Despite this, it is commonly employed in the management of intubated patients by physiotherapists who empirically perceive the technique to be effective in mobilizing secretions and improving atelectasis. It is commonly used in a gravity-assisted drainage position with the addition of chest wall vibrations on expiration. The mechanisms by which this treatment may enhance mucociliary clearance are undoubtedly multifactorial. Clearly more research is necessary to establish the reliability, safety and efficacy of the technique, especially compared with other modalities of treatment including positioning, exercise and mobilization. More results from randomized controlled trials using large subject numbers, possibly at a number of different centres, will enable the physiotherapist to make informed treatment choices for individual patients in the critical care setting.

\footnotetext{
Acknowledgements. The authors wishes to thank S. Berney and J. Nosworthy for their helpful comments and suggestions in editing this manuscript and $\mathrm{C}$. Vaughan for organizing patients during the time of writing.
}

\section{References}

1. Tan I, Oh T. Mechanical ventilatory support. In: Oh T, ed.Intensive Care Manual. 4th Ed. Oxford, Butterworth Heinemann, 1997; p. 246.

2. Jones A. Physiotherapy in intensive care. In: Oh T, ed.Intensive Care Manual. 4th Ed. Oxford, Butterworth Heinemann, 1997; pp. 26-31.

3. Spearman C, Sheldon R, Egan D. Mechanical ventilation. In: Spearman C, Sheldon R, Egan D, eds. Egan's Fundamentals of Respiratory Therapy. 4th Ed. St Louis, CV Mosby 1982; pp. 601-602.

4. Meduri U, Mauldin G, Wunderink R, Leeper K, Tolley E. Causes of fever and pulmonary densities in patients with clinical manifestations of ventilator-associated pneumonia. Chest 1994; 106: 221-235.

5. Fagon J, Chastre J, Hance A, Domart Y, Gilbert C, Trouillet J. Evaluation of patients suspected of having nosocomial pneumonia: are invasive procedures necessary for accurate decision making? Chest 1993; 103: 547553.

6. Ciesla N. Chest physical therapy for patients in the intensive care unit. Phys Ther 1996; 76: 609-625.

7. Windsor H, Harrison G, Nicholson T. "Bag squeezing": 
a physiotherapeutic technique. Med J Aust 1972; 2: 829-832.

8. McCarren B. Manual hyperinflation: a description of the technique. Aust J Physiotherapy 1996; 42: 203-208.

9. Singer M, Vermaat J, Hall G, Latter G, Patel M. Haemodynamic effects of manual hyperinflation in critically mechanically ventilated patients. Chest 1994; 106: 11821187.

10. Clement A, Hubsch S. Chest physiotherapy by the "bag squeezing" method. Physiotherapy 1968; 54: 355-359.

11. King D, Morrell A. A survey on manual hyperinflation as a physiotherapy technique in intensive care units. Physiotherapy 1992; 78: 747-750.

12. Jones A, Hutchinson R, Oh T. Chest physiotherapy practice in intensive care units in Australia, the UK and Hong Kong. Physiotherapy Theory Pract 1992; 8: 39-47.

13. Webber B, Pryor J. Physiotherapy skills: techniques and adjuncts. In: Webber B, Pryor J, eds. Physiotherapy for respiratory and Cardiac Problems. London, Churchill Livingstone, 1993; pp. 157-158.

14. Nunn J. Applied respiratory Physiology. 3rd Ed. London, Butterworths, 1987; pp. 31-32.

15. Marini J. Tidal volume, PEEP, and barotrauma - an open and shut case? Chest 1996; 109: 302-304.

16. Marcy T. Barotrauma: detection, recognition, and management. Chest 1993; 104: 578-584.

17. Dreyfuss D, Saumon G. Barotrauma is volutrauma, but which volume is the one responsible? Intensive Care Med 1992; 18: 139-141.

18. Haake R, Schlictig R, Ulstad D, Henschen R. Barotrauma: pathophysiology, risk factors, and prevention. Chest 1987; 91: 608-613.

19. Nunn J. Applied Respiratory Physiology. 3rd Ed. London, Butterworths, 1987; pp. 33.

20. Hack I, Katz C, Eales C. Airway pressure changes during "bag squeezing". S African J Physiotherapy 1980; 36: 9799.

21. Smith K, Jenkins S, Patman S, Lau K. Manual hyperinflation: consistency and modification of the technique by physiotherapists. Proceedings, 5th National Cardiothoracic Physiotherapy conference Perth, Australia 1997. Perth, Australian Physiotherapy Association Western Australia Branch, 36.

22. King M, Philips D, Zidulka A, Chang H. Tracheal mucus clearance in high frequency oscillation. Am Rev Respir Dis 1984; 130: 703-706.

23. Jones A, Jones R, Bacon-Shone J. A comparison of expiratory flow rates in two breathing circuits used for manual hyperinflation of the lungs. Physiotherapy 1991; 77: 593-597.

24. MacLean D, Drummond G, Macpherson C, McLaren G, Prescott R. Maximum expiratory airflow during chest physiotherapy on ventilated patients before and after the application of an abdominal binder. Intensive Care Med 1989; 15: 396-399.

25. Hess D, Goff G, Johnson K. The effect of hand size, resuscitator brand, and use of two hands on volumes delivered during adult bag-valve ventilation. Respiratory Care 1989; 34: 805-810.

26. Rothen H, Sporre B, Engberg G, Wegenius G, Hedstierna $\mathrm{G}$. Re-expansion of atelectasis during general anaesthesia: a computed tomography study. Br J Anaesthesia 1993; 71: 788-795.

27. Clarke S. Rationale of airway clearance. Eur Respir $J$ 1989; 7: 509-603.

28. Hardy K. A review of airway clearance: new techniques, indications and recommendations. Respiratory Care 1994; 39: 441-453.

29. Benjamin R, Kim C, Chapman G, Sachner M. Mechanical ventilation can remove bronchial secretions by two-phase gas liquid transport. Chest 1994; 86: 284.

30. Kim C, Iglesias A, Rodriguez C. Mucus transport by twophase gas-liquid flow mechanism during periodic flow. Am Rev Respir Dis 1984; 129: A373.

31. Sackner M, Kim C. Phasic flow mechanism of mucus clearance. Eur J Respir Dis 1987; 71: Suppl. 153, 159164.

32. Chopra S, Taplin G, Simmons D, Robinson G, Elam D, Coulson A. Effects of hydration and physical therapy on tracheal transport velocity. Am Rev Respir Dis 1977; 115: 1009-1114.

33. Konrad F, Schreiber T, Brecht-Kraus D, Georgieff M. Mucociliary transport in ICU patients. Chest 1994; 105: 237-241.

34. Foster W, Langenbach E, Bergofsky E. Respiratory drugs influence lung mucociliary clearance in central and peripheral ciliated airways. Chest 1981; 80: 877-880.

35. Landa J, Amikam B, Sackner M. Pathogenesis and prevention of tracheobronchial erosions occurring with suction. Am Rev Respir Dis 1971; 103: 875-876.

36. Hodgson C, Denehy L, Ntoumenopoulos G, Santamaria J, Carroll S. The acute effects of manual hyperinflation in critically ill patients. Eur Respir J 1996; Suppl. 23, 37s.

37. Stiller K, Jenkins S, Grant R, Geake T, Taylor J, Hall B. Acute lobar atelectasis: a comparison of five physiotherapy regimens. Physiotherapy Theory Pract 1996; 12: 197-209.

38. Wong J, Keens T, Wannamaker E. Effects of gravity in tracheal transport rates in normal subjects and in patients with cystic fibrosis. Paediatrics 1977; 60: 146-152.

39. Pryor J. Mucociliary clearance. In: Alison J, Ellis E, eds. Key Issues in Cardiorespiratory Physiotherapy. Wiltshire, Butterworth Heinemann, 1992; pp. 105-130.

40. Nelson H. Postural drainage of the lungs. Br Med J 1934; 2: $251-255$.

41. Sutton P, Parker R, Webber B. Assessment of the forced expiratory technique, postural drainage and directed coughing in chest physiotherapy. Eur J Respir Dis 1983; 64: 62-68.

42. Hofmeyr J, Webber B, Hodson M. Evaluation of positive expiratory pressure as an adjunct to chest physiotherapy in the treatment of cystic fibrosis. Thorax 1986; 41:951-954.

43. Pavia D. The role of chest physiotherapy in mucous hypersecretion. Lung 1990; 168: Suppl., 614-621.

44. Jones A, Hutchinson R, Oh T. Effects of bagging and percussion on total static compliance of the respiratory system. Physiotherapy 1992; 78: 661-666.

45. Tucker B, Jenkins S. The effect of breathing exercises with body positioning on regional lung ventilation. Aust $J$ Physiotherapy 1996; 42: 219-226.

46. Ada L, Canning C, Paratz J. Care of the unconscious head injured patient. In: Ada L, Canning C, eds. Key Issues in Neurological Physiotherapy. Oxford, Butterworth Heinemann 1990; pp. 249-287.

47. Webber B, Pryor J. Physiotherapy skills: techniques and adjuncts. In: Webber B, Pryor Jeds. Physiotherapy for Respiratory and Cardiac Problems. London, Churchill Livingstone, 1993; p. 124.

48. Imle P, Klemic N. Methods of airway clearance: coughing and suctioning. In: Mackenzie C, ed. Chest Physiotherapy in the Intensive Care Unit. 2nd Ed. Baltimore, Williams and Wilkins, 1989 p. 180.

49. Ackerman M. The use of bolus normal saline instillation 
in artificial airways; is it useful or necessary? Heart Lung 1985; 14: 505-506.

50. Dean E. Oxygen transport: a physiologically - based conceptual framework for the practice of cardiopulmonary physiotherapy. Physiotherapy 1994; 80: 347-355.

51. Ntoumenopoulos G. Topical issues in cardiopulmonary physiotherapy. Physiotherapy 1995; 81: 92-94.

52. Marini J, Pierson D, Hudson L. Acute lobar atelectasis: a prospective comparison of fibreoptic bronchoscopy and respiratory therapy. Am RevRespir Dis 1979; 119:971-978.

53. Stiller K, Geake T, Taylor J, Grant R, Hall B. Acute lobar atelectasis a comparison of two chest physiotherapy regimens. Chest 1990; 98: 1336-1340.

54. Scholton D, Novak R, Snyder J. Directed manual recruitment of collapsed lung in intubated and non intubated patients. Am Surgeon 1985; 51: 330-335.

55. Tweed W, Phua W, Chong E, Lim E, Lee T. Tidal volume, lung hyperinflation and arterial oxygenation during general anaesthesia. Anaesthesia Intensive Care 1993; 21: 806-810.
56. Stone K, Talaganis S, Preusser B, Gonyon D. Efffect of lung hyperinflation and endotracheal suctioning on heart rate and rhythm in patients after coronary bypass graft surgery. Heart and Lung 1991; 20: 443-450.

57. Laws A, McIntyre R. Chest physiotherapy: a physiological assessment during intermittent positive pressure ventilation in respiratory failure. Can Anaes Soc J 1969; 16: 487-492.

58. Mackenzie C, Shin B. Cardiorespiratory function before and after chest physiotherapy in mechanically ventilated patients with post traumatic respiratory failure. Crit Care Med 1985; 13: 483-486.

59. Novak R, Schumaker L, Synder J, Pinksy M. Do periodic hyperinflations improve gas exchange in patients with hypoxaemic respiratory failure. Crit Care Med 1987; 15 : 1081-1085.

60. Gormezano J, Branthwaite M. Effects of pysiotherapy during intermittent positive pressure ventilation. Changes in arterial blood gas tensions. Anesthesia 1972; 27: 258264. 